\title{
An essential role of KREPB4 in RNA editing and structural integrity of the editosome in Trypanosoma brucei
}

\author{
VINOD KUMAR BABBARWAL, ${ }^{1,3}$ MICHELE FLECK, ${ }^{1}$ NANCY LEWIS ERNST, ${ }^{1}$ ACHIM SCHNAUFER, ${ }^{1}$ \\ and KENNETH STUART ${ }^{1,2}$ \\ ${ }^{1}$ Seattle Biomedical Research Institute, Seattle, Washington 98109, USA \\ ${ }^{2}$ Department of Pathobiology, University of Washington, Seattle, Washington 98195, USA
}

\begin{abstract}
RNA editing in the sleeping sickness parasite Trypanosoma brucei remodels mitochondrial transcripts by the addition and deletion of uridylates as specified by guide RNAs. Editing is catalyzed by at least three distinct $\sim 20 S$ multiprotein editosomes, all of which contain KREPB4, a protein with RNase III and Pumilio motifs. RNAi repression of KREPB4 expression in procyclic forms (PFs) strongly inhibited growth and in vivo RNA editing, greatly diminished the abundance of 20S editosomes, reduced cellular levels of editosome proteins, and generated $\sim 5-10 S$ editosome subcomplexes. Editing TUTase, exoUase, and RNA ligase activities were largely shifted from $\sim 20 S$ to $\sim 5-10 S$ fractions of cellular lysates. Insertion and deletion endonuclease activities in $\sim 20 S$ fractions were strongly reduced upon KREPB4 repression but were not detected in the 5-10S subcomplex fraction. Abundance of MRP1 and RBP16 proteins, which appear to be involved in RNA processing but are not components of the $20 S$ editosome, was unaltered upon KREPB4 repression. These data suggest that KREPB4 is important for the structural integrity of $\sim 20 S$ editosomes, editing endonuclease activity, and the viability of PF $T$. brucei cells.
\end{abstract}

Keywords: Trypanosoma brucei; trypanosomatids; RNA editing; editosome; RNase III; endonuclease

\section{INTRODUCTION}

RNA editing in the mitochondria of kinetoplastids, flagellated protozoa that include the sleeping sickness parasite, Trypanosoma brucei, inserts and deletes uridylates (Us) at numerous sites in mRNAs as specified by guide RNAs (gRNAs) (Madison-Antenucci et al. 2002; Simpson et al. 2004; Stuart et al. 2005). The $5^{\prime}$ region of each gRNA forms a duplex with its cognate pre-mRNA adjacent to the sequence that will be edited as specified by the information region of the gRNA. Editing at each site starts with endonucleolytic cleavage of the editing site by KREN1, KREN2, or perhaps KREPB2 (Carnes et al. 2005; Trotter et al. 2005; Panigrahi et al. 2006; Kang et al. 2006) followed by the addition of Us by the KRET2 3 '-terminal uridylyl transferase (TUTase) (Ernst et al. 2003; Aphasizhev et al. 2003c) or the deletion of Us by the KREX1 U-specific 3' exoribonuclease (exoUase) (Kang et al. 2005), depending on whether it is an insertion

\footnotetext{
${ }^{3}$ Present address: Invitrogen BioServices India Pvt. Ltd., Bangalore 560 066, Karnataka, India.

Reprint requests to: Kenneth Stuart, Seattle Biomedical Research Institute, 307 Westlake Avenue North, Suite 500, Seattle, WA 98109; e-mail: kenneth.stuart@sbri.org; fax: (206) 256-7229.

Article published online ahead of print. Article and publication date are at http://www.rnajournal.org/cgi/doi/10.1261/rna.327707.
}

or deletion site, and subsequent rejoining of the processed mRNA fragments by KREL1 or KREL2 RNA ligases (McManus et al. 2001; Rusché et al. 2001; Schnaufer et al. 2001; Palazzo et al. 2003). Since each gRNA specifies the editing of several sites, in some cases both insertion and deletion sites, multiple cycles of the enzyme-catalyzed steps are required to edit the region specified by a single gRNA. Indeed, most mRNAs require many gRNAs to specify the editing that results in the mature translatable mRNA. In addition to the several catalytic activities required for editing, numerous molecular interactions must occur to position and move the mRNA/gRNA duplex during the editing process.

Multiprotein editosomes that sediment at $\sim 20 S$ on glycerol gradients catalyze RNA editing and contain at least 20 proteins that have been identified in trypanosomes and Leishmania (Rusche et al. 1997; Panigrahi et al. 2001a,b, 2003b, 2006; Aphasizhev et al. 2003a). The KREN1 and KREN2 proteins, which have RNase III motifs, have deletion and insertion editing site endonucleolytic function, respectively (Carnes et al. 2005; Trotter et al. 2005; Kang et al. 2006; Panigrahi et al. 2006). KREPB2, which is related to KREN1 and KREN2 and also has an RNase III motif, may have an endonucleolytic function as well (J. Carnes, J. Trotter, A. Pelton, N.L. Ernst, and K. Stuart, unpubl.). These endonucleases occur in very similar but physically 
distinct editosomes (Panigrahi et al. 2006). KRET2, KREX1, KREL1, and KREL2 function in TUTase, ExoUase, and ligase activities, respectively (McManus et al. 2001; Rusché et al. 2001; Schnaufer et al. 2001, 2003; Ernst et al. 2003; Palazzo et al. 2003; Aphasizhev et al. 2003c; Kang et al. 2005). Other editosome proteins lack catalytic motifs but have motifs suggestive of RNA and/or protein interaction. These include KREPA1, which interacts with KRET2 TUTase and KREL2 ligase and can occur as an insertion subcomplex, and KREPA2, which interacts with KREX2 and KREL1 and can occur as a deletion subcomplex (Schnaufer et al. 2003). Repression of KREPA1 expression results in loss of insertion editing and shift of editosomes to a lower $\mathrm{S}$ value (Drozdz et al. 2002; O’Hearn et al. 2003), and similarly, repression of KREPA2 expression results in loss of deletion editing and partial disruption of $20 \mathrm{~S}$ editosomes (Huang et al. 2002). RNA interference (RNAi) inactivation of KREPA4 expression results in the loss of $20 \mathrm{~S}$ editosomes and, along with preferential binding in vitro of recombinant protein to gRNA with a $3^{\prime} \mathrm{U}$ tail, suggests roles for this protein in RNA and/or protein interaction (Salavati et al. 2006). The B family of editosome proteins KREPB1-8 all have U1-like zinc finger motifs in their N-terminal regions (including $\mathrm{KREN1}=\mathrm{KREPB} 1$ and $\mathrm{KREN} 2=\mathrm{KREPB} 3$, which were renamed when endonuclease activity was shown). KREPB4 and KREPB5 also have central RNase III-like motifs, although they are substantially diverged from the canonical motif in KREN1, KREN2, and KREPB2 (Panigrahi et al. 2003b; Worthey et al. 2003). KREPB4 and KREPB5 also contain a more C-terminal Pumilio motif that overlaps the C-terminal region of the RNase III-like motif, a first example of this overlap arrangement (Worthey et al. 2003). Repression of KREPB5 expression in bloodstream form (BF) T. brucei resulted in generation of editosome subcomplexes and their ultimate loss, and consequently loss of editing and cell growth (Wang et al. 2003).

Other complexes and proteins that are not editosome components may function in or indirectly affect editing. These include the KRET1 complex that may add the $3^{\prime}$ oligo (U) gRNA tails (Aphasizhev et al. 2002, 2003c), the MRP complex that may anneal mRNA and gRNA (Müller and Göringer 2002; Aphasizhev et al. 2003b; Vondruskova et al. 2005; Schumacher et al. 2006), and RBP16, which may function in aspects of RNA processing (Pelletier and Read 2003), as well as REAP1 and TbRGG1, which have uncertain functions (Vanhamme et al. 1998; Madison-Antenucci and Hajduk 2001). The differential editing during the life cycle also implies that protein accessory factors may transiently interact with the editosome to mediate this process (Stuart et al. 1997).

We report here that repression of KREPB4 expression inhibited cell growth in procyclic insect form parasites (PFs), indicating its importance for cell viability. The levels of MRP1 and RBP16 proteins were unaffected in KREPB4repressed cells. KREPB4 repression resulted in alterations of editosome integrity and abundance as well as reduced in vivo edited mRNAs. Importantly, it also resulted in the inability to detect in vitro endonuclease activity in editosome subcomplexes that had other in vitro editing activities. These studies indicate a crucial role for KREPB4 in structural integrity of editosomes that affects endonuclease activity and hence editing in vivo and consequently cell viability.

\section{RESULTS}

\section{KREPB4 is important for cell growth and RNA editing}

The roles of KREPB4 in parasite viability and RNA editing were examined using cell lines in which gene expression was conditionally repressed by RNAi. A pZJM RNAi construct that contains 742 base pairs (bp) of the KREPB4 coding sequence was stably integrated into the nontranscribed spacer of the rDNA locus of PF $T$. brucei for tetracycline (tet)-inducible expression of double-stranded RNA (dsRNA). Activation of the dsRNA expression inhibited cell growth and reduced KREPB4 mRNA abundance (Fig. 1). Uninduced cells grew normally in both cases. Activation of a 538-bp dsRNA corresponding to the $5^{\prime}$ region of KREPB4 mRNA including 29 bp of the $5^{\prime}$ untranslated region (UTR) did not inhibit growth (data not shown). Following expression of the 742-bp dsRNA, the growth of PFs was strongly inhibited and eventually ceased. Inhibition of growth was evident by day 5 and reached a maximum by day 10 (Fig. 1A), resulting in almost complete cessation of growth, although the cells remained alive and motile during the time they were observed. KREPB4 protein levels could not be directly assessed in the RNAi cells due to the lack of an antibody against KREPB4. Thus, knockdown of KREPB4 expression by RNAi resulted in a growth defect for PF T. brucei.

To determine the effect of KREPB4 repression on RNA editing in vivo, quantitative real-time RT-PCR (qPCR) analysis of RNA isolated $3 \mathrm{~d}$ after induction of RNAi revealed that editing was substantially reduced in vivo (Fig. 1B). The level of KREPB4 mRNA was decreased by $\sim 45 \%$ in induced RNAi cells compared to the noninduced cells, and edited A6, RSP12, MURF2, and COII mRNA levels were reduced by a similar amount. In contrast, the levels of pre-edited mRNAs were increased upon knockdown of KREPB4. The mRNA levels of KREPB5, encoding a related protein, KREN2, encoding another B-family editosome protein that also contains an RNase III motif, and ND4, a never edited mitochondrial transcript, were essentially unchanged. Overall, these data indicate that KREB4 is important for editing in vivo.

\section{KREPB4 repression disrupts the $\sim 20 \mathrm{2}$ editosome}

Repression of KREPB4 expression strongly affected editosome integrity and resulted in a shift of complexes from 
A

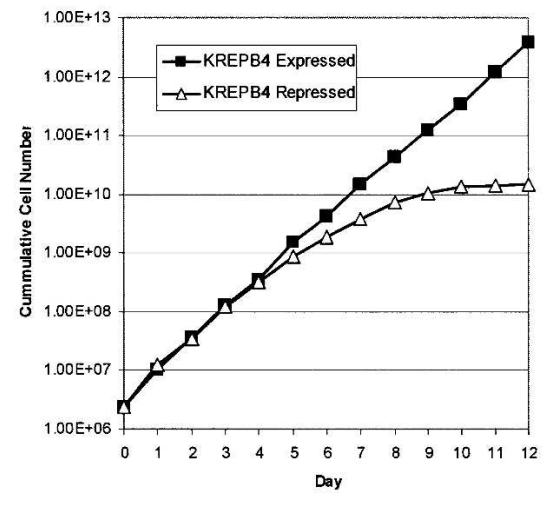

B

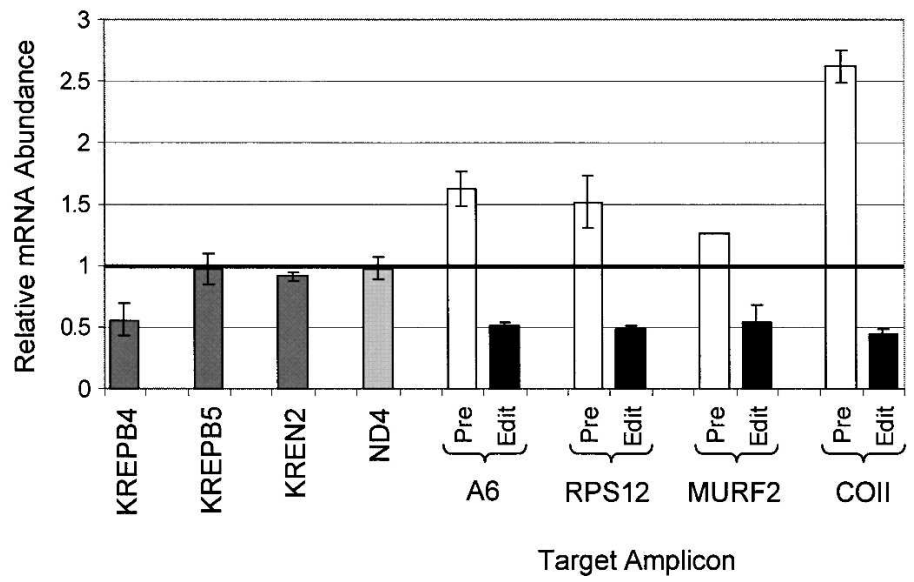

FIGURE 1. Loss of KREPB4 by RNAi induction inhibits T. brucei cell growth and reduces edited RNA abundance in vivo. (A) Growth curve of a PF RNAi cell line in which KREPB4 is expressed (absence of RNAi induction, closed squares) or repressed after RNAi induction with tet (open triangles). Cell growth was monitored for $12 \mathrm{~d}$, and the cumulative cell number represents the normalization of cell densities by multiplication with the dilution factor. $(B)$ Real-time quantitative RT-PCR analysis of total RNA isolated from cells after induction of KREPB4 RNAi for $3 \mathrm{~d}$. The abundance of pre-edited (open bars) and edited (black bars) mitochondrial RNAs from repressed cells are shown relative to that from cells in which KREPB4 is expressed. The relative abundance of KREPB4, KREPB5, and KREN2 mRNAs (dark gray bars) and never edited ND4 mRNA (light gray bar) is also shown. The RNA levels were normalized to $18 \mathrm{~S}$ rRNA. The thick horizontal black line intersecting at 1 on the $Y$-axis indicates no change in mRNA level, with anything above or below this line representing an increase or decrease in mRNA levels, respectively. Error bars, SD calculated from at least three replicates.

$\sim 20 \mathrm{~S}$ to $\sim 5-10 \mathrm{~S}$. Whole cell lysates of RNAi cells in which KREPB4 was expressed or repressed for 3 and $6 \mathrm{~d}$ were fractionated on glycerol gradients and examined by Western analysis using monoclonal antibodies (MAbs) specific for four editosome proteins or by auto-adenylation of the KREL1 and KREL2 editing ligases using radiolabeled ATP (Fig. 2). The KREPA1, KREPA2, KREPA3, KREL1, and KREL2 editosome proteins that cosediment at $\sim 20 \mathrm{~S}$ in control cells were dramatically reduced, and most of the remaining protein shifted to $\sim 5-10 \mathrm{~S}$ after 3 and $6 \mathrm{~d}$ of RNAi induction. Some editosome complexes remained at $\sim 20$ S, as revealed primarily by the more sensitive (and less quantitative) adenylation assay. Western analyses of the same glycerol gradient fractions with polyclonal antibodies (PAbs) specific for MRP1 and RBP16, which are not components of $\sim 20 \mathrm{~S}$ editosomes but may transiently associate with it and have functions in RNA editing (Müller and Göringer 2002; Aphasizhev et al. 2003b; Pelletier and Read 2003; Vondruskova et al. 2005; Schumacher et al. 2006), showed no difference in protein levels or change in sedimentation upon KREPB4 repression. Reprobing of the membranes with MAbs against hsp70 confirmed equal loading. Thus, KREPB4 is important for the structural integrity and stability of $\sim 20$ S editosomes.

\section{KREPB4 repression affects RNA editing in vitro}

Repression of KREPB4 significantly affected in vitro RNA editing activities in extracts prepared from RNAi cells (Figs. 3, 4). Fractions from the same glycerol gradients that were used for the Western and adenylation assays were used for precleaved editing assays that analyze the $\mathrm{U}$ addition, $\mathrm{U}$ deletion, and RNA ligation activities of editing. These assays use trimeric RNAs that mimic the editing substrate after cleavage of the pre-mRNA by endonuclease (Igo et al. 2000, 2002). The TUTase and ligase activities of precleaved insertion editing (Fig. 3A) and exoUase and ligase activities of precleaved deletion editing (Fig. 3B) were shifted from $\sim 20$ S to $\sim 5-10 S 3$ and $6 \mathrm{~d}$ post-induction in KREPB4 RNAi cells. This mirrors the shift of editosome proteins observed by Western and adenylation analyses (Fig. 2). Note that the editing ligases, in particular KREL1, also ligate unprocessed input RNA as previously observed (Igo et al. 2000, 2002; Huang et al. 2001; Schnaufer et al. 2003). RNA to which two Us were added, the edited product, and the ligated input RNAs with no additional Us were present in similar amounts in precleaved insertion assays of samples from cells in which KREPB4 was expressed or repressed for 3 and $6 \mathrm{~d}$. Similarly, RNA with four Us removed, the edited product, and the ligated input RNAs without deletion of four Us were present in similar abundance in expressed or repressed cells in precleaved deletion assays. However, in this case the $-2 \mathrm{U}$ and $-3 \mathrm{U}$ products were present in greater amounts at lower $S$ values in fractions from nonrepressed cells, possibly due to nucleases other than the exoUase, as observed previously (Wang et al. 2003; Salavati et al. 2006). The observation that the $\sim 5-10 S$ fractions from RNAi-induced cells were as active in precleaved editing assays as the $\sim 20 \mathrm{~S}$ fractions from control cells, despite a reduced abundance of editosome proteins, was unexpected. It might reflect altered 


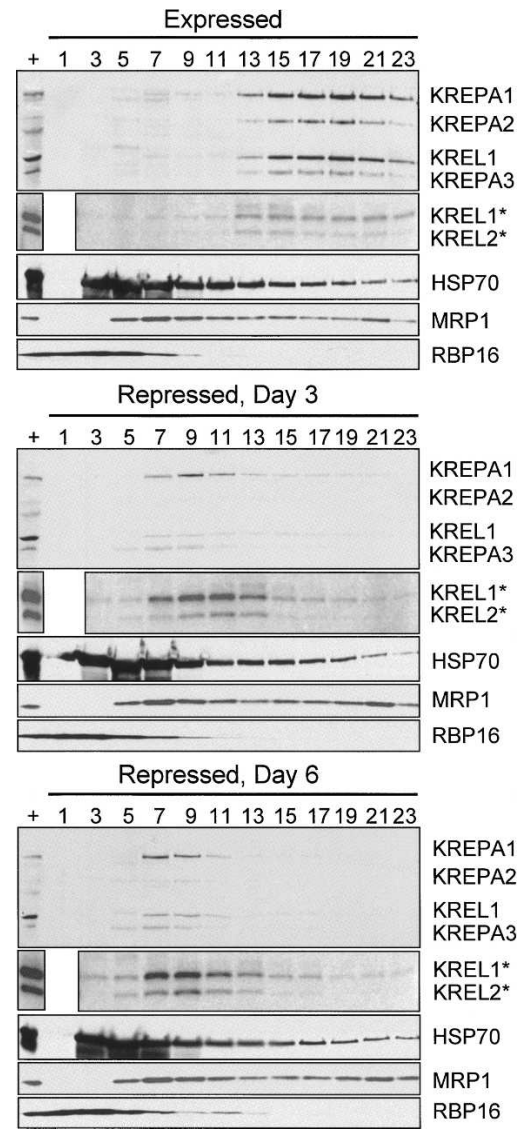

FIGURE 2. Effect of KREPB4 repression on editosome integrity. Western analyses and adenylation assays (KREL1* and KREL2 ${ }^{\star}$ ) of glycerol gradient fractions (numbered from top to bottom) from whole cell lysates of KREPB4 RNAi cells grown in the absence (expressed) or presence (repressed) of tet for 3 and $6 \mathrm{~d}$ are shown. A fraction that contains $\sim 20$ S editosomes was used as a positive control $(+)$. The Western analyses used a cocktail of four MAbs specific for core editosome proteins as indicated, and the blots were stripped and reprobed with MRP1 and RBP16 PAbs and HSP70 MAbs, the latter serving as a loading control.

catalytic properties of the enzymes in the absence of fully assembled 20S complexes or enhanced access to the synthetic RNA substrates in these in vitro assays, perhaps due to reduced association with endogenous gRNA and/or mRNA substrate. To assess endonuclease activity in these glycerol gradient fractions, we used in vitro assays that were optimized for the generation of cleavage products instead of edited products (Carnes et al. 2005). In contrast to the precleaved activities, no gRNA-specific endonuclease activities were detected in the $\sim 5-10 S$ fractions upon KREB4 repression. Rather, these activities were merely lost or greatly reduced from the $\sim 20 \mathrm{~S}$ glycerol gradient fractions (Fig. 4A-C). This suggests that the cleavage activities either directly involve KREPB4 or require assembly of intact $\sim 20$ S editosomes. Thus, the partial loss of the catalytic activities associated with editing upon repression of KREPB4 further confirms its role in RNA editing.

\section{DISCUSSION}

This study shows that KREPB4 is a critical component of the $\sim 20 \mathrm{~S}$ editosome of T. brucei. Inhibition by RNAi of its expression resulted in a severe growth defect in the PF (insect) life cycle stage. The RNAi knockdown resulted in the specific reduction of editosome proteins and edited mRNAs, and the generation of editosome subcomplexes. However, levels of MRP1 and RBP16, which are not components of the $\sim 20 \mathrm{~S}$ editosome (Aphasizhev et al. 2003a, b; Pelletier and Read 2003; Panigrahi et al. 2006), were unaffected. The TUTase, exoUase, and ligase activities were retained by the subcomplexes, but endonuclease activities were either much reduced or not detected at all. Thus, KREPB4 is important for the structural integrity of the $\sim 20 \mathrm{~S}$ editosome and, as a consequence, cell viability in PF T. brucei.

KREPB4 knockdown had a much greater effect on the endonuclease activities than on the other editing catalytic
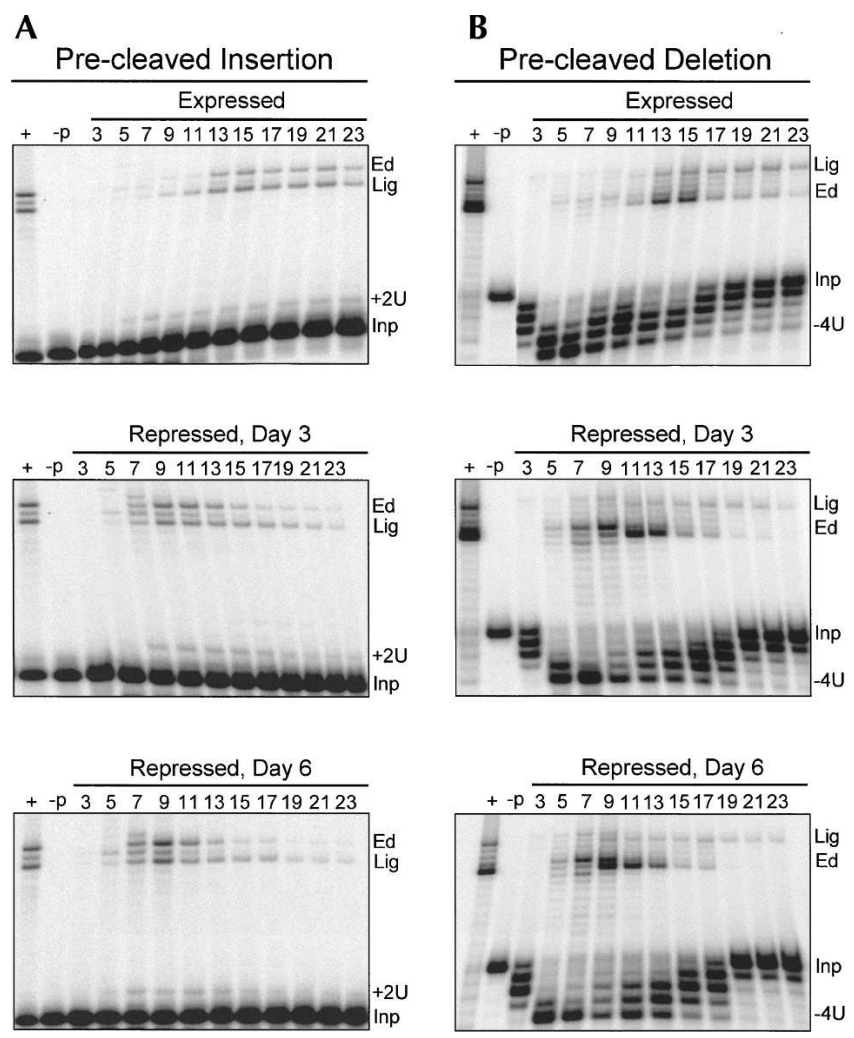

FIGURE 3. Repression of KREPB4 expression in RNAi cells affects RNA editing catalytic activities in vitro. Glycerol gradient fractions (fraction 1, top) from whole cell lysates of KREPB4 RNAi cells grown in the absence (expressed) or in the presence (repressed) of tet were assayed for in vitro precleaved insertion $(A)$ or precleaved deletion $(B)$ editing activities. The radiolabeled input RNAs (Inp), to which two Us are added $(+2 \mathrm{U})$, or from which four Us are removed $(-4 \mathrm{U})$, ligated products of unprocessed $5^{\prime}$ and $3^{\prime}$ input RNAs (Lig), and edited (Ed) products are indicated. Positive control reactions $(+)$ were performed using a fraction of $\sim 20$ S editosome that contains peak editing activity, which was omitted from negative control reactions $(-p)$. 
A Insertion Endonuclease

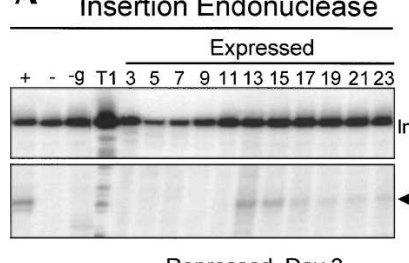

Repressed, Day 3

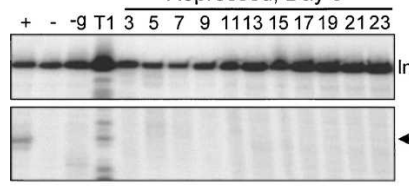

Repressed, Day 6
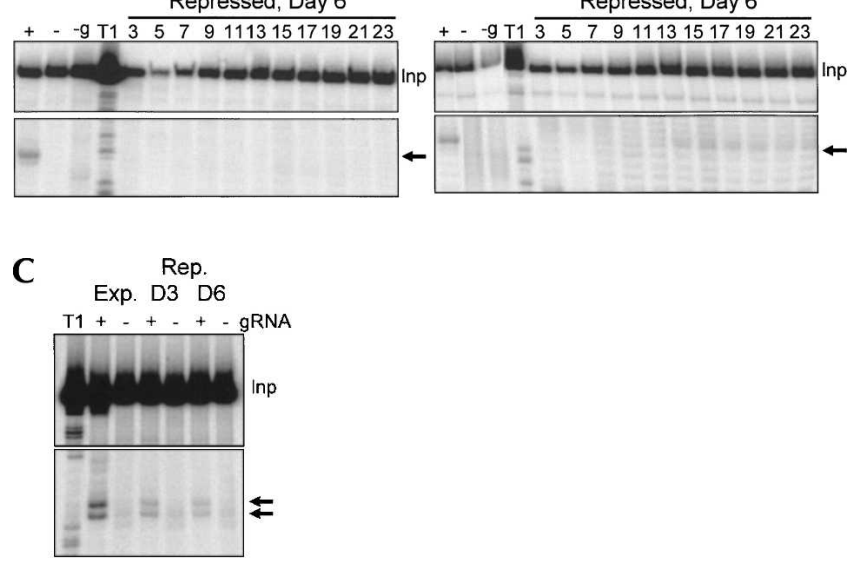

FIGURE 4. Repression of KREPB4 expression in PF RNAi cells reduces insertion and deletion endonuclease activities in vitro. Insertion $(A)$ and deletion $(B)$ editing assays, optimized for generation of cleavage product, were performed using the same glycerol gradient fractions that were used in the previous precleaved editing assays. The upper panels show the radiolabeled input RNA (Inp), and the lower panels show the cleavage product; the blank middle region of the gels is not shown. Both endonuclease assays were based on the A6 substrate and require two RNAs: an mRNA fragment (radiolabeled at the 3' end) and a gRNA. Positive control reactions $(+)$ were performed using a fraction of $\sim 20 \mathrm{~S}$ editosome that contains peak editing activity, which was omitted from negative control reactions $(-)$. The position of the specific, gRNA-directed cleavage product is indicated by an arrow. gRNA was omitted from control reactions $(-\mathrm{g})$. RNase T1digested substrate RNA (T1) was used as a marker to determine where substrate RNA was cleaved. (C) Glycerol gradient fraction 17 from expressed (Exp.) and repressed conditions (Rep., days 3 and 6) was analyzed for deletion endonuclease activity in the presence or absence of gRNA. The double band is the result of some size heterogeneity in the radiolabeled input RNA (also apparent in the T1 ladder).

activities. The insertion and deletion site endonuclease activities were dramatically reduced and were only observed in the $20 \mathrm{~S}$ region of the glycerol gradients (Fig. 4), in contrast to the TUTase, exoUase, and ligase activities that were retained but shifted from $\sim 20 S$ to $\sim 5-10 S$ in knockdown cells (Fig. 3), as did the editosome proteins (Fig. 2). This suggests that KREPB4 is important for the endonuclease step of editing as well as editosome integrity. This is consistent with its RNase III, U1-like zinc finger, and Pumilio motifs (Worthey et al. 2003). RNase III enzymes typically function with the active site formed at a dimer interface (Gan et al. 2006). It seems likely that KREPB4 may not directly catalyze the cleavage since the KREN1 and KREN2 editosome proteins, which also contain RNase III motifs, appear to catalyze endonucleolytic cleavage of deletion and insertion sites, respectively, and since mutation of conserved residues in the RNase III motifs ablates these activities in vitro and eliminates editing in vivo (Carnes et al. 2005; Trotter et al. 2005; Panigrahi et al. 2006). Indeed, recombinant Leishmania major KREN1 has been reported to catalyze endonucleolytic cleavage, although high concentrations of protein were required (Kang et al. 2006). Editing cleaves the mRNA strand of the mRNA/gRNA heteroduplex while other RNase III enzymes typically cleave both strands of an RNA duplex. These data, along with the less conserved RNase III motif in KREPB4 (Worthey et al. 2003), raise the possibility that it may form a heterodimer with KREN1 and/or KREN2 (and/ or perhaps KREPB2) to create a catalytic site that efficiently and specifically cleaves only the mRNA strand of the mRNA/gRNA duplex of deletion or insertion (or cis) editing sites, respectively. We recently found that there are at least three compositionally and functionally distinct $\sim 20$ S editosomes that primarily differ with respect to the presence of KREN1, KREN2, or KREPB2 and other proteins as well as endonuclease activity (Panigrahi et al. 2006). However, all contain KREPB4, and the related KREPB5 protein (see below). The relative roles of the KREPB4 and KREPB5 proteins and their physical and functional interactions with KREN1, KREN2, and KREPB2 in the different editosomes are uncertain.

KREPB4 plays a role in the structural integrity of the $\sim 20$ S editosome that appears to affect the association of editosome subcomplexes. Insertion and deletion editing subcomplexes that are between $5 \mathrm{~S}$ and $10 \mathrm{~S}$ are generated upon expression of tagged editosomes proteins (Schnaufer et al. 2003; Panigrahi et al. 2006). Their compositions differ somewhat depending on which protein is tagged. The composition and size of the subcomplexes presumably reflects the structural organization of the tagged protein in the editosome. For example, tagged KREL1 results in a deletion subcomplex that contains KREPA2, KREL1, and KREX2, and tagged KREL2 results in an insertion subcomplex that contains KREPA1, KREL2, and KRET2 (Schnaufer et al. 2003). The size and activities of the subcomplexes resulting from reduced KREPB4 expression (Fig. 2) resemble these insertion and deletion subcomplexes and suggest that KREPB4 may be involved in linking these subcomplexes. The U1-like zinc finger motif in KREPB4 (Worthey et al. 2003) could be involved in such a role.

Other editosome proteins are also essential for editosome structure. KREPB5 is related to KREPB4, and repression of its expression results in a phenotype much like that of KREPB4 knockdowns but more extreme, probably due to a more complete repression (Wang et al. 2003). Subcomplexes were generated in BFs within $12 \mathrm{~h}$, followed 
by the complete loss of editosomes and editing and subsequently cell death. This implies a role for KREPB5 that is similar to that of KREPB4. Repression of KREPA4 expression resulted in the complete loss of the $\sim 20$ S editosome and editing activities (Salavati et al. 2006) while repression of KREPA1, KREPA2, and KREX1 expression resulted in generation of subcomplexes and loss of several catalytic activities (Drozdz et al. 2002; Huang et al. 2002; O’Hearn et al. 2003; Kang et al. 2005). Thus, these proteins have roles in editosome integrity. Inactivation of KREL1 expression, while lethal, did not generate subcomplexes or eliminate editosomes (Schnaufer et al. 2001; Stuart et al. 2002), and down-regulation of KREPA3 expression resulted in the loss of both endo- and exoribonuclease activities with no apparent change in the sedimentation or protein levels of $\sim 20$ S editosomes (Brecht et al. 2005).

This study extends the list of T. brucei editosome proteins shown to be essential for editing and hence cell viability (Rusché et al. 2001; Schnaufer et al. 2001; Drozdz et al. 2002; Huang et al. 2002; Wang et al. 2003; O'Hearn et al. 2003; Brecht et al. 2005; Carnes et al. 2005; Deng et al. 2005; Kang et al. 2005; Trotter et al. 2005; Salavati et al. 2006). The only exceptions known are KREPB2 and KREL2, where substantial RNAi knockdowns did not block growth or editing (Drozdz et al. 2002; Gao and Simpson 2003; O'Hearn et al. 2003; Trotter et al. 2005). The related editosome proteins may have compensated for the loss of these proteins.

Overall, this study shows that KREPB4 is an integral T. brucei editosome component that is important for its structure and essential for editing and hence cell viability. While its location in the editosome, its binding partners, and its specific function remain to be elucidated, KREPB4 appears to play an important role in the association of insertion and deletion editosome subcomplexes and in the first catalytic step of editing, endonucleolytic cleavage of the mRNA.

\section{MATERIALS AND METHODS}

\section{Plasmid constructs and transfections}

Constructs were generated for expressing tet-inducible dsRNA for KREPB4 by inserting fragments of the gene into the Xhol/HindIII sites of the RNAi vector pZJM (Wang et al. 2000). A 742-bp fragment corresponding to the middle of the KREPB4 coding sequence resulted in knockdown of expression while a 538-bp fragment that includes 29 bp of the 5' UTR did not. The fragments were PCR-amplified from T. brucei 427 strain genomic DNA. The 538-bp fragment was amplified using 5'-ATACTCGA GATATAGTGAGGCAGTATCTG-3' and $5^{\prime}$-ATAAAGCTTTCGC CCAGGAACATAT- $3^{\prime}$, and the 742-bp fragment was amplified with 5'-ATACTCGAGTACGTTGACGAGGTCACTCA-3' and 5'-ATAAAGCTTTCACTTCTGGTCCACCAGAG-3'. Restriction sites for each construct are italicized. The resulting PCR products were cloned into pGEM-T Easy (Promega), released with XhoI and HindIII, and subcloned into a similarly digested pZJM vector.
PF T. brucei cells were grown in SDM-79 containing 10\% FBS. RNAi cell lines were generated in the 29.13 strain (Wirtz et al. 1999) by transfection with $10 \mu \mathrm{g}$ of NotI-linearized pZJM construct, using a published procedure (Wirtz et al. 1999). Transfectants were selected in the presence of $15 \mu \mathrm{g} / \mathrm{mL}$ of $\mathrm{G} 418,25 \mu \mathrm{g} / \mathrm{mL}$ of hygromycin, and $2.5 \mu \mathrm{g} / \mathrm{mL}$ of phleomycin. The resultant stable cell line was designated KREPB4 RNAi. RNAi was induced with $1 \mu \mathrm{g} / \mathrm{mL}$ tet, and the uninduced and induced cells were counted daily to obtain growth curves. Cells were maintained between $2.3 \times 10^{6}$ and $3.5 \times 10^{7}$ cells $/ \mathrm{mL}$.

\section{RNA isolation and real-time RT-PCR}

Quantitative real-time RT-PCR (qPCR) was carried out to assess pre-edited and edited mRNA levels essentially as described (Carnes et al. 2005). Briefly, total RNA was isolated from cells grown in the presence or absence of tet using Trizol reagent as described by the manufacturer (GIBCO-BRL). Ten micrograms of total RNA were treated with DNase I using the DNA-free kit (Ambion). The integrity of the DNase-treated RNA was confirmed using an RNA nanochip on a Bioanalyzer (Agilent Technologies). The cDNA templates for the qPCR were reverse transcribed from $4.5 \mu \mathrm{g}$ of RNA using random hexamers and Taqman reverse transcription reagents (Applied Biosystems) in a $30 \mu \mathrm{L}$ reaction. Control reactions without reverse transcriptase were used to confirm the absence of contaminating genomic DNA. Primers for $\mathrm{qPCR}$ were designed using ABI Primer Express v2.0 software. The sequences of all the primers for each pre-edited and edited mRNA used were described previously (Carnes et al. 2005), except KREPB4 forward 5'-TCCAGTACC GACCAAACCTTTG-3' and KREPB4 reverse 5'-GCACGTGTGA GACCGGAAT-3'. The cDNA reactions were diluted between 1:7 and 1:50, and amplified in $25 \mu \mathrm{L}$ reactions containing $12.5 \mu \mathrm{L}$ of SYBR Green PCR Master Mix (Applied Biosystems), $2.5 \mu \mathrm{L}$ of a cDNA template (or - RT control), and $5 \mu \mathrm{L}$ each of $1.5 \mu \mathrm{M}$ forward and reverse primers in 96-well plates using the ABI Prism 7000 sequence detection system (Applied Biosystems). Amplification conditions for all reactions were $2 \mathrm{~min}$ at $50^{\circ} \mathrm{C}$ and $10 \mathrm{~min}$ at $95^{\circ} \mathrm{C}$, followed by 40 cycles of $15 \mathrm{sec}$ at $95^{\circ} \mathrm{C}$ and $1 \mathrm{~min}$ at $60^{\circ} \mathrm{C}$. Each reaction was performed in triplicate. Thermal dissociation curves confirmed that the PCR generated a single amplicon. Analysis was carried out by using the Pfaffl method, with PCR efficiencies calculated by linear regression with LinRegPCR software (Pfaffl 2001; Ramakers et al. 2003). Relative changes for target RNAs were determined after normalization to $18 \mathrm{~S}$ rRNA and were expressed as fold-change with respect to control cells. The specificity of the KREPB4 amplicon was confirmed by direct sequencing using the same set of KREPB4 gene-specific primers that was used in $\mathrm{qPCR}$.

\section{Glycerol gradient fractionation}

A total of $2 \times 10^{9}$ KREPB4 RNAi cells, grown in the presence or absence of tet, were lysed in $500 \mu \mathrm{L}$ of IP buffer $(10 \mathrm{mM}$ Tris-Cl at $\mathrm{pH}$ 7.6, $10 \mathrm{mM} \mathrm{MgCl}_{2}, 300 \mathrm{mM} \mathrm{KCl}, 1 \%$ Triton X-100) containing a cocktail of three protease inhibitors $(5 \mu \mathrm{g} / \mathrm{mL}$ pepstatin, $10 \mu \mathrm{g} / \mathrm{mL}$ leupeptin, $1 \mathrm{mM}$ Pefabloc). The cell lysates were cleared by centrifugation at $13,000 \mathrm{rpm}$ for $15 \mathrm{~min}$ at $4^{\circ} \mathrm{C}$ and then loaded onto $11 \mathrm{~mL}$ of $10 \%-30 \%$ ( $\mathrm{vol} / \mathrm{vol}$ ) glycerol gradients. The gradients were centrifuged at 38,000 rpm for $12 \mathrm{~h}$ 
at $4^{\circ} \mathrm{C}$ in a Beckman SW40 rotor. After the centrifugation, $500 \mu \mathrm{L}$ fractions were collected from the top of the gradients, flash frozen in liquid nitrogen, and stored at $-80^{\circ} \mathrm{C}$ until further analysis.

\section{Western analysis and adenylation assay}

Alternate glycerol gradient fractions $(40 \mu \mathrm{L})$ were resolved by $10 \%$ SDS-PAGE (Bio-Rad) and transferred onto a methanol-treated PVDF membrane. The membrane was blocked in $10 \%$ nonfat milk powder in PBST (10 mM phosphate buffer at $\mathrm{pH} 7.2,150 \mathrm{mM}$ $\mathrm{NaCl}$, and $0.1 \%$ Tween 20 ) overnight at $4^{\circ} \mathrm{C}$. The membrane was washed with PBST three times and probed with a cocktail of MAbs specific for KREPA1, KREPA2, KREL1, and KREPA3 (Panigrahi et al. 2001b), an anti-hsp70 MAb (Panigrahi et al. 2003a), or PAbs against MRP1 (Vondruskova et al. 2005) or RBP16 (Hayman and Read 1999) in 5\% nonfat milk powder in PBST for $2 \mathrm{~h}$ at room temperature. The membrane was then washed three times with PBST and incubated with horseradish peroxidase-conjugated anti-mouse immunoglobin $\mathrm{G}$ (Bio-Rad) in $1 \%$ nonfat milk powder in PBST. The membrane was washed with PBST three times and then developed using an ECL kit as specified by the manufacturer (Amersham). Adenylation of RNA editing ligases (KREL1 and KREL2) was assayed as described previously (Sabatini and Hajduk 1995). The reaction products were separated by $10 \%$ SDS-PAGE (Bio-Rad), and the radiolabeled proteins were visualized using a PhosphorImager (Molecular Dynamics).

\section{RNA editing assays}

Glycerol gradient fractions from KREPB4 RNAi cells in which RNAi was induced or uninduced were assayed using in vitro editing assays. Full-round insertion and deletion assays based on ATPase synthase subunit 6 (A6) were modified to enhance formation of the endonucleolytic cleavage product and performed as described previously (Carnes et al. 2005; Trotter et al. 2005). Insertion editing assays used A6-eES1 pre-mRNA and gA6[14] gRNA. Deletion editing reactions used the A6short/TAG.1 pre-mRNA and D34 gRNA, which is a derivative of D33' (Cruz-Reyes et al. 2001). Precleaved insertion and deletion activities were assayed as previously described by using $5^{\prime}$-labeled $5^{\prime}$ CL18 and $3^{\prime}$ CL13pp with gPCA6-2A RNAs (Igo et al. 2000) and 5'-labeled U5 5'CL and U5 $3^{\prime} \mathrm{CL}$ with gA6[14]PC-del RNAs (Igo et al. 2002), respectively. Reaction products were resolved on $11 \%$ acrylamide with $7 \mathrm{M}$ urea gels and visualized using a PhosphorImager (Molecular Dynamics).

\section{ACKNOWLEDGMENTS}

We thank G. Cross and E. Wirtz for providing T. brucei strain 29.13, P. Englund for the pZJM vector, J. Lukes and L. Read for MRP1 and RBP16 PAbs, respectively, and members of the Stuart laboratory for helpful suggestions. This work was supported by NIH grant GM42188 to K.S. and extended work supported by NIH grant AI014102 to K.S.

Received October 4, 2006; accepted February 5, 2007.

\section{REFERENCES}

Aphasizhev, R., Sbicego, S., Peris, M., Jang, S.H., Aphasizheva, I., Simpson, A.M., Rivlin, A., and Simpson, L. 2002. Trypanosome mitochondrial $3^{\prime}$-terminal uridylyl transferase (TUTase): The key enzyme in U-insertion/deletion RNA editing. Cell 108: 637-648.

Aphasizhev, R., Aphasizheva, I., Nelson, R.E., Gao, G., Simpson, A.M., Kang, X., Falick, A.M., Sbicego, S., and Simpson, L. 2003a. Isolation of a U-insertion/deletion editing complex from Leishmania tarentolae mitochondria. EMBO J. 22: 913-924.

Aphasizhev, R., Aphasizheva, I., Nelson, R.E., and Simpson, L. $2003 \mathrm{~b}$. A $100-\mathrm{kD}$ complex of two RNA-binding proteins from mitochondria of Leishmania tarentolae catalyzes RNA annealing and interacts with several RNA editing components. RNA 9: 62-76.

Aphasizhev, R., Aphasizheva, I., and Simpson, L. 2003c. A tale of two TUTases. Proc. Natl. Acad. Sci. 100: 10617-10622.

Brecht, M., Niemann, M., Schlüter, E., Müller, U.F., Stuart, K., and Göringer, H.U. 2005. TbMP42, a protein component of the RNA editing complex in African trypanosomes has endo-exoribonuclease activity. Mol. Cell 17: 621-630.

Carnes, J., Trotter, J.R., Ernst, N.L., Steinberg, A.G., and Stuart, K. 2005. An essential RNase III insertion editing endonuclease in Trypanosoma brucei. Proc. Natl. Acad. Sci. 102: 16614-16619.

Cruz-Reyes, J., Zhelonkina, A., Rusché, L., and Sollner-Webb, B. 2001. Trypanosome RNA editing: Simple guide RNA features enhance U deletion 100-fold. Mol. Cell. Biol. 21: 884-892.

Deng, J., Ernst, N.L., Turley, S., Stuart, K.D., and Hol, W.G.J. 2005. Structural basis for UTP specificity of RNA Editing TUTases from Trypanosoma brucei. EMBO J. 24: 4007-4017.

Drozdz, M., Palazzo, S.S., Salavati, R., O’Rear, J., Clayton, C., and Stuart, K. 2002. TbMP81 is required for RNA editing in Trypanosoma brucei. EMBO J. 21: 1791-1799.

Ernst, N.L., Panicucci, B., Igo Jr., R.P., Panigrahi, A.K., Salavati, R., and Stuart, K. 2003. TbMP57 is a 3'-terminal uridylyl transferase (TUTase) of the Trypanosoma brucei editosome. Mol. Cell 11: $1525-1536$.

Gan, J., Tropea, J.E., Austin, B.P., Court, D.L., Waugh, D.S., and Ji, X. 2006. Structural insight into the mechanism of double-stranded RNA processing by ribonuclease III. Cell 124: 355-366.

Gao, G. and Simpson, L. 2003. Is the Trypanosoma brucei REL1 RNA ligase specific for U-deletion RNA editing, and is the REL2 RNA ligase specific for U-insertion editing? J. Biol. Chem. 278: 27570-27574.

Hayman, M.L. and Read, L.K. 1999. Trypanosoma brucei RBP16 is a mitochondrial Y-box family protein with guide RNA binding activity. J. Biol. Chem. 274: 12067-12074.

Huang, C.E., Cruz-Reyes, J., Zhelonkina, A.G., O’Hearn, S., Wirtz, E., and Sollner-Webb, B. 2001. Roles for ligases in the RNA editing complex of Trypanosoma brucei: Band IV is needed for U-deletion and RNA repair. EMBO J. 20: 4694-4703.

Huang, C.E., O'Hearn, S.F., and Sollner-Webb, B. 2002. Assembly and function of the RNA editing complex in Trypanosoma brucei requires band III protein. Mol. Cell. Biol. 22: 3194-3203.

Igo Jr., R.P., Palazzo, S.S., Burgess, M.L.K., Panigrahi, A.K., and Stuart, K. 2000. Uridylate addition and RNA ligation contribute to the specificity of kinteoplastid insertion RNA editing. Mol. Cell. Biol. 20: 8447-8457.

Igo Jr., R.P., Weston, D.S., Ernst, N.L., Panigrahi, A.K., Salavati, R., and Stuart, K. 2002. Role of uridylate-specific exoribonuclease activity in Trypanosoma brucei RNA editing. Eukaryot. Cell 1: $112-118$.

Kang, X., Rogers, K., Gao, G., Falick, A.M., Zhou, S., and Simpson, L. 2005. Reconstitution of uridine-deletion precleaved RNA editing with two recombinant enzymes. Proc. Natl. Acad. Sci. 102: 1017-1022.

Kang, X., Gao, G., Rogers, K., Falick, A.M., Zhou, S., and Simpson, L. 2006. Reconstitution of full-round uridine-deletion RNA editing with three recombinant proteins. Proc. Natl. Acad. Sci. 103: 13944-13949.

Madison-Antenucci, S. and Hajduk, S. 2001. RNA editing-associated protein 1 is an RNA binding protein with specificity for preedited mRNA. Mol. Cell 7: 879-886. 
Madison-Antenucci, S., Grams, J., and Hajduk, S.L. 2002. Editing machines: The complexities of trypanosome RNA editing. Cell 108: $435-438$.

McManus, M.T., Shimamura, M., Grams, J., and Hajduk, S.L. 2001. Identification of candidate mitochondrial RNA editing ligases from Trypanosoma brucei. RNA 7: 167-175.

Müller, U.F. and Göringer, H.U. 2002. Mechanism of the gBP21mediated RNA/RNA annealing reaction: Matchmaking and charge reduction. Nucleic Acids Res. 30: 447-455.

O'Hearn, S., Huang, C.E., Hemann, M., Zhelonkina, A., and SollnerWebb, B. 2003. Trypanosoma brucei RNA editing complex: Band II is structurally critical and maintains band V ligase, which is nonessential. Mol. Cell. Biol. 23: 7909-7919.

Palazzo, S.S., Panigrahi, A.K., Igo Jr., R.P., Salavati, R., and Stuart, K. 2003. Kinetoplastid RNA editing ligases: Complex association, characterization, and substrate requirements. Mol. Biochem. Parasitol. 127: 161-167.

Panigrahi, A.K., Gygi, S., Ernst, N., Igo Jr., R.P., Palazzo, S.S., Schnaufer, A., Weston, D., Carmean, N., Salavati, R., Aebersold, R., et al. 2001a. Association of two novel proteins, TbMP52 and TbMP48, with the Trypanosoma brucei RNA editing complex. Mol. Cell. Biol. 21: 380-389.

Panigrahi, A.K., Schnaufer, A., Carmean, N., Igo Jr., R.P., Gygi, S.P., Ernst, N.L., Palazzo, S.S., Weston, D.S., Aebersold, R., Salavati, R., et al. 2001b. Four related proteins of the Trypanosoma brucei RNA editing complex. Mol. Cell. Biol. 21: 6833-6840.

Panigrahi, A.K., Allen, T.E., Haynes, P.A., Gygi, S.P., and Stuart, K. 2003a. Mass spectrometric analysis of the editosome and other multiprotein complexes in Trypanosoma brucei. J. Am. Soc. Mass Spectrom. 14: 728-735.

Panigrahi, A.K., Schnaufer, A., Ernst, N.L., Wang, B., Carmean, N., Salavati, R., and Stuart, K. 2003b. Identification of novel components of Trypanosoma brucei editosomes. RNA 9: 484-492.

Panigrahi, A.K., Ernst, N.L., Domingo, G.J., Fleck, M., Salavati, R., and Stuart, K.D. 2006. Compositionally and functionally distinct editosomes in Trypanosoma brucei. RNA 12: 1038-1049.

Pelletier, M. and Read, L.K. 2003. RBP16 is a multifunctional gene regulatory protein involved in editing and stabilization of specific mitochondrial mRNAs in Trypanosoma brucei. RNA 9: 457-468.

Pfaffl, M.W. 2001. A new mathematical model for relative quantification in real-time RT-PCR. Nucleic Acids Res. 29: e45.

Ramakers, C., Ruijter, J.M., Deprez, R.H.L., and Moorman, A.F.M. 2003. Assumption-free analysis of quantitative real-time polymerase chain reaction (PCR) data. Neurosci. Lett. 339: 62-66.

Rusche, L.N., Cruz-Reyes, J., Piller, K.J., and Sollner-Webb, B. 1997. Purification of a functional enzymatic editing complex from Trypanosoma brucei mitochondria. EMBO J. 16: 4069-4081.

Rusché, L.N., Huang, C.E., Piller, K.J., Hemann, M., Wirtz, E., and Sollner-Webb, B. 2001. The two RNA ligases of the Trypanosoma brucei RNA editing complex: Cloning the essential band IV gene and identifying the band V gene. Mol. Cell. Biol. 21: 979-989.

Sabatini, R. and Hajduk, S.L. 1995. RNA ligase and its involvement in guide RNA/mRNA chimera formation. Evidence for a cleavageligation mechanism of Trypanosoma brucei mRNA editing. J. Biol. Chem. 270: 7233-7240.
Salavati, R., Ernst, N.L., O'Rear, J., Gilliam, T., Tarun Jr., S., and Stuart, K. 2006. KREPA4, an RNA binding protein essential for editosome integrity and survival of Trypanosoma brucei. RNA 12: 819-831.

Schnaufer, A., Panigrahi, A.K., Panicucci, B., Igo Jr., R.P., Salavati, R., and Stuart, K. 2001. An RNA ligase essential for RNA editing and survival of the bloodstream form of Trypanosoma brucei. Science 291: 2159-2162.

Schnaufer, A., Ernst, N., O’Rear, J., Salavati, R., and Stuart, K. 2003. Separate insertion and deletion subcomplexes of the Trypanosoma brucei RNA editing complex. Mol. Cell 12: 307-319.

Schumacher, M.A., Karamooz, E., Zikova, A., Trantirek, L., and Lukes, J. 2006. Crystal structures of Trypanosoma brucei MRP1/ MRP2 guide-RNA-binding complex reveals RNA matchmaking mechanism. Cell 126: 701-711.

Simpson, L., Aphasizhev, R., Gao, G., and Kang, X. 2004. Mitochondrial proteins and complexes in Leishmania and Trypanosoma involved in U-insertion/deletion RNA editing. RNA 10: 159-170.

Stuart, K., Allen, T.E., Heidmann, S., and Seiwert, S.D. 1997. RNA editing in kinetoplastid protozoa. Microbiol. Mol. Biol. Rev. 61: 105-120.

Stuart, K.D., Panigrahi, A.K., Schnaufer, A., Drozdz, M., Clayton, C., and Salavati, R. 2002. Composition of the editing complex of Trypanosoma brucei. Philos. Trans. R. Soc. Lond. B Biol. Sci. 357: 71-79.

Stuart, K.D., Schnaufer, A., Ernst, N.L., and Panigrahi, A.K. 2005. Complex management: RNA editing in trypanosomes. Trends Biochem. Sci. 30: 97-105.

Trotter, J.R., Ernst, N.L., Carnes, J., Panicucci, B., and Stuart, K. 2005. A deletion site editing endonuclease in Trypanosoma brucei. Mol. Cell 20: 403-412.

Vanhamme, L., Perez-Morga, D., Marchal, C., Speijer, D., Lambert, L., Geuskens, M., Alexandre, S., Ismaïli, N., Göringer, U., Benne, R., et al. 1998. Trypanosoma brucei TBRGG1, a mitochondrial oligo(u)-binding protein that colocalizes with an in vitro RNA editing activity. J. Biol. Chem. 273: 21825-21833.

Vondruskova, E., Van den Burg, J., Zikova, A., Ernst, N.L., Stuart, K., Benne, R., and Lukes, J. 2005. RNA interference analyses suggest a transcript-specific regulatory role for mitochondrial RNA-binding proteins MRP1 and MRP2 in RNA editing and other RNA processing in Trypanosoma brucei. J. Biol. Chem. 280: 2429-2438.

Wang, Z., Morris, J.C., Drew, M.E., and Englund, P.T. 2000. Inhibition of Trypanosoma brucei gene expression by RNA interference using an integratable vector with opposing T7 promoters. J. Biol. Chem. 275: 40174-40179.

Wang, B., Ernst, N.L., Palazzo, S.S., Panigrahi, A.K., Salavati, R., and Stuart, K. 2003. TbMP44 is essential for RNA editing and structural integrity of the editosome in Trypanosoma brucei. Eukaryot. Cell 2: 578-587.

Wirtz, E., Leal, S., Ochatt, C., and Cross, G.A.M. 1999. A tightly regulated inducible expression system for conditional gene knock-outs and dominant-negative genetics in Trypanosoma brucei. Mol. Biochem. Parasitol. 99: 89-101.

Worthey, E.A., Schnaufer, A., Mian, I.S., Stuart, K., and Salavati, R. 2003. Comparative analysis of editosome proteins in trypanosomatids. Nucleic Acids Res. 31: 6392-6408. 

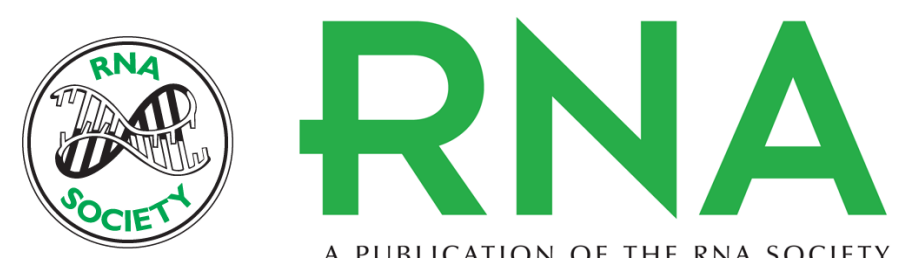

A PUBLICATION OF THE RNA SOCIETY

\section{An essential role of KREPB4 in RNA editing and structural integrity of the editosome in Trypanosoma brucei}

Vinod Kumar Babbarwal, Michele Fleck, Nancy Lewis Ernst, et al.

RNA 2007 13: 737-744 originally published online March 16, 2007

Access the most recent version at doi:10.1261/rna.327707

\section{References This article cites 51 articles, 32 of which can be accessed free at: http://rnajournal.cshlp.org/content/13/5/737.full.html\#ref-list-1}

License Email Alerting $\begin{aligned} & \text { Receive free email alerts when new articles cite this article - sign up in the box at the } \\ & \text { Service }\end{aligned}$ top right corner of the article or click here.

To subscribe to $R N A$ go to:

http://rnajournal.cshlp.org/subscriptions 